\title{
Architecture as Landscape
}

\author{
Yasmine Abbas ${ }^{1}$ \\ ${ }^{1}$ The Pennsylvania State University, University Park, PA 16801, USA
}

\begin{abstract}
This study constitutes the latest reflection on pedagogical research and experimental pedagogical projects involving the representation, design, and computation of ambiances. Led by the author at various architecture schools in France, Japan, and the United States, these creative explorations involving drawings and models offer ways to realize, feel, and fabricate architecture. The projects described were conducted in 2018 in courses offered by the Department of Architecture, Stuckeman School, College of Arts and Architecture at the Pennsylvania State University. They show that architectural productions are not static objects, but instead render a dynamic landscape itself nested within a changing milieu. Through these projects, by looking closely at the parameters of spatial effects, students engaged in processes of design taking movement into account in meaningful ways.
\end{abstract}

\section{Milieu in motion}

Considering architecture as a landscape implies appreciating motion, in its many incarnations, as essential to the making of a moving (fluctuating and touching) atmosphere that enchants us and connects us to the world. Individuals experience space through movement, get in touch with their surroundings through the means of sensory perception. Further, most of the elements that constitute the atmosphere of a place are dynamic. A strong light washing across a vivid pink wall [1: p. 149] creates, for example, a particular effect that contributes to the prevailing ambiance at a given time. Buildings themselves undergo transformations that participate in changing perceptions of the architectural object: a building's function (and form) changes over time and marks caused by wear and tear give surfaces a certain patina. The materials in use, the building orientation, the locations of openings, and the articulation of interior spaces each contribute to the creation of microclimates (e.g., warm and humid as in greenhouses), sensations (e.g., shivering brought on by a draught) and atmospheres. A building is a fluid milieu nested in a larger one. Each to one degree or another adjusts to the other.

Architects have investigated the sensory and experiential relationships between architecture and surrounding landscapes by exploring phenomena that occur in the interplay of material and light, material and sound, and color and light and by using "prospect and refuge" strategies to stage buildings as shelters [2]. What other ingredients, easily perceptible and less perceptible, could architectural designers experiment with to create atmospheric spaces? The movement of humans and non-humans, animals, insects, etc., in a milifeu; the temperature; the relative humidity; the direction and velocity of air flow; the presence, 
strength, and nature of fragrances; the qualities of materials including their ability to absorb or reflect light, which, in turn, impacts perceptions of color; and many more invisible constituents - ultraviolet or infrared light for example - contribute to the making of fluid spaces that are experienced dynamically.

In this study, we examine the performative potentials of architectural drawings and models that bring architecture closer to landscape architecture. Overall, we demonstrate ways to design and teach for spatial delight based on a range of sensory and atmospheric parameters. Described are several experimentations that took place in 2018 in courses offered by the Department of Architecture at the Stuckeman School of Architecture and Landscape Architecture, College of Arts and Architecture, the Pennsylvania State University.

\section{Atmospheric grammar}

Since 2014, in multiple pedagogical frameworks, i.e. research seminars, workshops, intensive studios, and single assignments over the timeline of a semester-long architecture studio, conducted in different cultural contexts (France, Japan, and the United States), undergraduate or graduate students, sometimes working together, have explored the potential of drawings and models to serve as both representational and projective atmospheric tools.

On the one hand, the cartography of ambiance [3] not only charts the landscape or "map[s] the intangible," as Stan Allen argues in his exploration of notations and diagrams [4: pp. 4069] but also seeks a "pattern language" [5], not of architectural forms, but of atmospheric conditions. By manipulating notational strategies, the cartography of ambiance offers a way to script "sensoryscapes" that pulls inspiration from the drawings of Bernard Tschumi [6], the collective Archizoom [7], and polymath Iannis Xenakis [8].

On the other hand, atmospheric devices or models explore given anticipated phenomena in a more immediate and tactile way than drawings do. They demonstrate, for example, the combined effect of light, materiality, and reflection as in Peter Zumthor's large-scale model for the Therme Vals [9]. Conceiving of a given model as a series or ensemble of models is meant to acknowledge the many and various effects that can be achieved using just one set of parameters.

Historian Mark Wigley argues that architectural representation is inherently atmospheric [10]. If we agree, then the cartographies of ambiances and atmospheric devices have a particular feel. Yet, they are also "operative" [11] or "generative" of atmospheric grammars that relate sensory and atmospheric parameters. They contribute to a deeper understanding of the relationship between architecture and landscape.

\subsection{The cartography of ambiance}

\subsubsection{The field}

"Practicing the landscape," understood as going to the field or experiencing a milieu in movement, is, for the architect, an important immersive and relational experience that $\mathrm{s} / \mathrm{he}$ embodies and translates into an architectural projection. The "field condition," as Allen calls it, "implies the acceptance of the real in all its messiness and unpredictability" [4: p. 217]. In the realm of contemporary "visual practices," which rely on computer programming capabilities, the field condition, as commonly illustrated by mesmerizing bird formations, is 
also preoccupied with localized types of relations between single elements [4]. So, as Allen writes, "form matters, but not so much the forms of things as the forms between things" [4: p. 218]. The field condition is inherently dynamic and literally "stages" an ambiance, contributing to what philosopher Gernot Böhme calls the "paradigm for an aesthetic of atmospheres" [12]. As an example, Jean Dubuffet's Coucou Bazar "practicables" construct on stage a dynamic field condition of lines and shapes [13] that relate in a variable manner.

In the context of the Atmospheres: Perception, Design and Fabrication spring 2018 course, the author challenged students to individually explore an atmospheric field condition, to stage an atmosphere based on the vivid memory of a place. The author asked students to devise an "atmospheric formula" incorporating a consideration of environmental aspects such as smell intensity, color, wind direction, and decibel level, and to create a twodimensional representation of the ambiance inspired by the popular representation of the NoStop City project by architecture collective Archizoom.

Andrea Branzi of Archizoom uses the grid as an "open field" [4] to represent "a continuous space without clear limits" [7: p. 130]. Clusters of "calligraphic signs, forming clouds" populate some areas of the grid [7]. The grid does not function as a traditional architecture plan. Instead, architectural ambiance or atmosphere is suggested (i.e., architecture in its gaseous form), represented as field of things within the structure of the grid. Archizoom's drawings, the group's political message aside, therefore, offered a good starting point for imagining how to visualize ambiances in two dimensions.

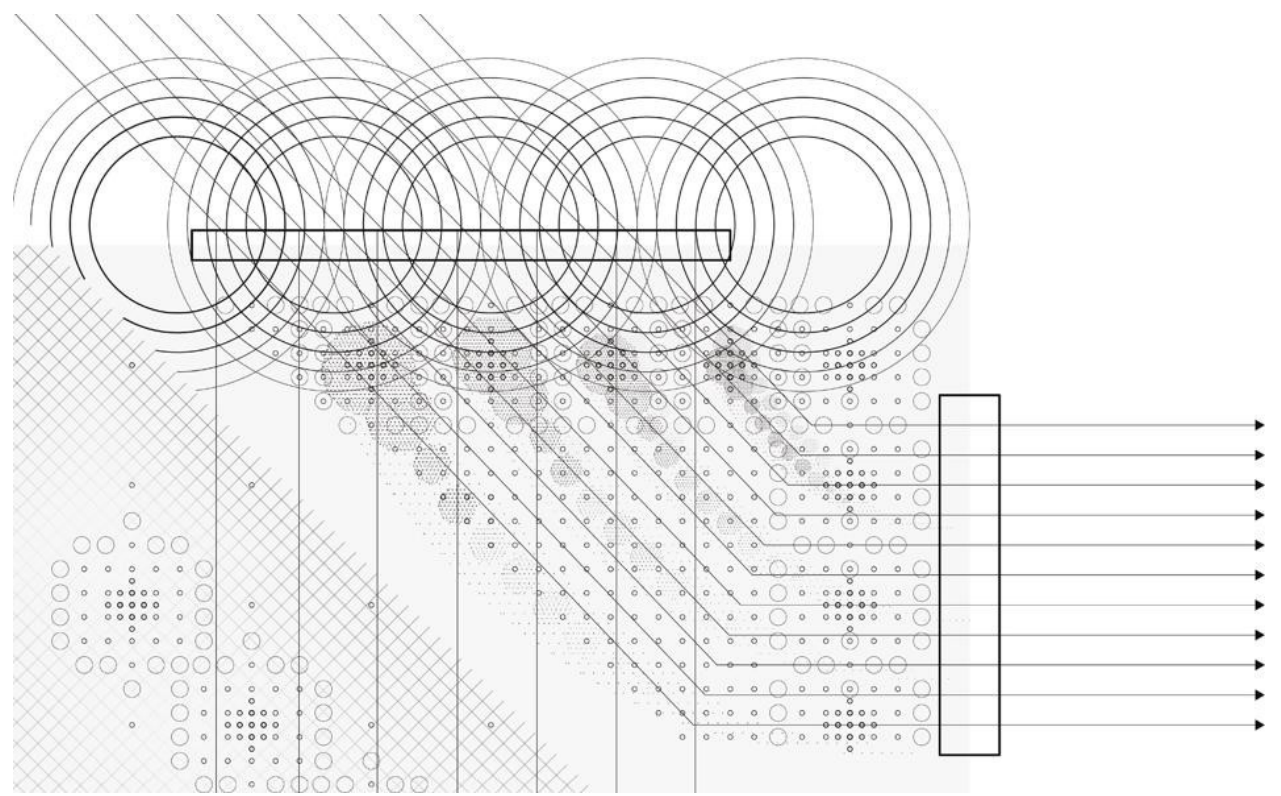

Fig. 1. Atmospheric map (excerpt) by In Pun. Image (C In Pun. 
The dynamic nature of atmospheres prompted everyone in the class to discuss ways to incorporate notational elements and other graphical techniques to indicate movement. In Pun, for example, decoded the atmosphere of a temple that she had once visited, which had greatly impressed her. To show the soft and fluid feel of the ambiance, the student used arrows to indicate the direction of the air flow, patterns that became lighter and smaller in scale as the scents they represented faded away, and concentric circles to signal the propagation of sound (Fig. 1). Atmospheric maps à la Archizoom called for more dynamic visualizations of atmospheres, for more "operative" than "representative" drawings [11], useful to guide the design of an ambiance, if not to replicate it. Atmospheres that "emanate" [10] from either architectural or landscape architecture arrangements are similar in nature, i.e., fluid (in their gaseous state) and temporal. Finding a process to embed mobility into a design to build meaningful atmospheres has driven this pedagogical research since 2014.

\subsubsection{From sensory mapping to architecture}

On a sunny Thursday afternoon in the fall of 2018, teams of students enrolled in their fourthyear architectural studio went to the field, to visit their project site. As a way to closely engage them with the context, they were asked to sample data related to each of the senses (each team selected a sense, and all senses needed to be addressed) using tools of their own choosing, from pencils and sticky notes to record imprints of textures to mobile phone applications for recoding decibel levels. Given the expanse of the project site and the time to be spent in the field (an afternoon), the students were directed to collect data within a given arbitrary grid of twelve feet by twelve feet with no architectural indication. This assignment was given at the beginning of the fall 2018 semester and served both the Architectural Design VI studio (co-taught with Nathaniel Quincy Belcher) and the Atmospheres: Representation, Design and Fabrication (optional) research seminar ${ }^{1}$.

In a manner similar to but not quite as codified as the scientific soil sampling in the Amazon forest described by Bruno Latour [14], the students took notes pertaining to the sensory data collected. They were then asked to code and map their data. For example, as a response to the assignment, a team of students created a soundscape map. Circles on the map, smaller to larger, indicated sound intensity, whereas color indicated the kind of sound. As a result, the loud sound that pedestrians generated by walking on hard surfaces rendered the circulation paths discernible throughout the site without the need to draw them in a conventional way. The soundscape map also revealed different patterns: for example, the concentration of sound in an area of the map, which raised questions about the reasons underlying the occurrence of such phenomena and increased the students' awareness of intangible effects.

Students who had elected to enroll in the atmospheres class used parametric modeling software to visualize the same dataset: they reported their data in an Excel document, which was later read by a Grasshopper script designed for the seminar, ${ }^{2}$ and through which patterns, concentrations, dips, and rises were revealed. The advantage of the software is its ability to manifest and spatialize the data.

\footnotetext{
${ }^{1}$ Department of Architecture, Stuckeman School of Architecture and Landscape Architecture, College of Arts and Architecture, The Pennsylvania State University.

${ }^{2}$ Many thanks to Grasshopper wizard Eduardo Raposoda Silva De Castro for his assistance
} 


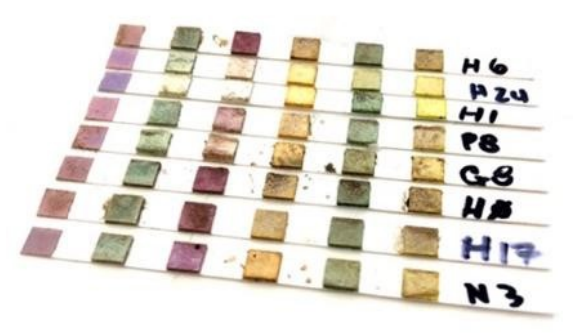

Fig. 2. Tray of pH samples collected by students Audrey Buck and Teagan Marron, fall 2018. Image (C) Author.

Sensory data collection has proven to be the easiest entry point to exploring the parameters of architectural ambiances. Students sample decibels and sound quality (mechanical, human, or natural sounds), textures (hard to soft), variations in canopy density (in connection to the sense of vision, the percentage of sky and foliage determined when taking a photograph looking up), or types of fragrances (plant-based, chemical, or else). However, collecting data related to the sense of taste is difficult. Given that this is the case, a team of students used the following approach: they collected soil samples, added water to them, and using off-the-shelf $\mathrm{pH}$ strips, determined the acidity or alkalinity of each (Fig. 2).

Through this investigation at the architectural studio, a new avenue of design inquiry opened up related to the impact of architecture on the landscape and the potential of spatial strategies for mitigating soil pollution. Based on the $\mathrm{pH}$ map (Fig. 3), the team decided to explore the flow of water on site, to design a roof capable of collecting rainwater and distributing it to the soil via specific landscape and architectural features at the ground level, and to select building materials (for example, copper or wood) to modify the $\mathrm{pH}$ of the water on contact. 


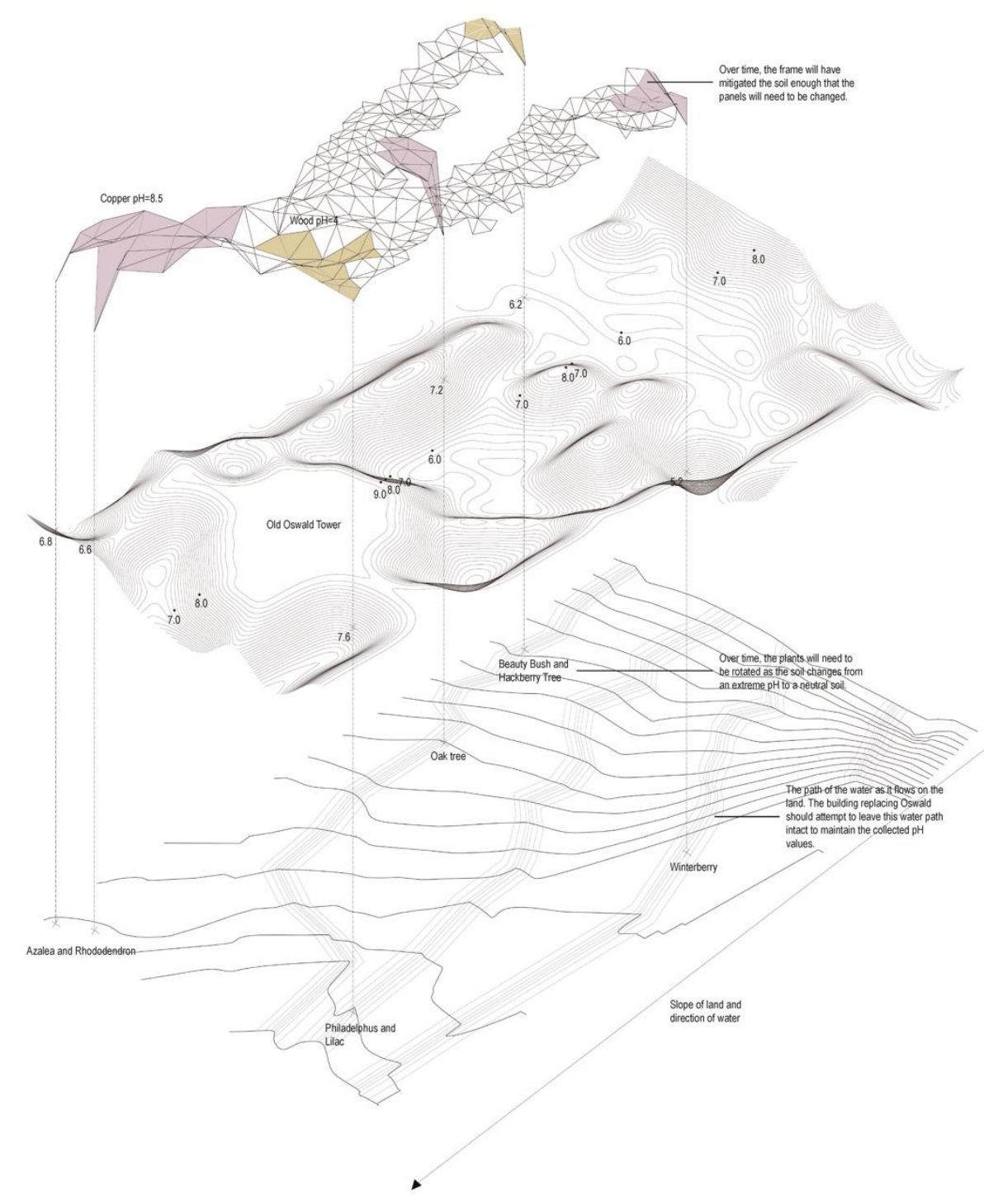

Fig. 3. Map of sampled $\mathrm{pH}$ and the roof imagined by Audrey Buck and Teagan Marron, fall 2018. Image (C) Audrey Buck and Teagan Marron.

The team, whose members were interested in minimizing the impact of architectural production on the natural environment, noted that when the $\mathrm{pH}$ of the soil had reached a "neutral" level, key elements of the building and the site-i.e., the building material of the roof and the locations of plants - would have to be changed to avoid a reverse effect. Thus, the students joined a broader conversation about architecture and the landscape through creating engaging spaces.

The meticulous (and strenuous) process of sensory data collection, however extensive and varied the data, will never be sufficient to capture the atmosphere of a place. Yet, the processes of collecting and analyzing data proved to be a worthy pedagogical exercise in terms of connecting students more closely to the context and helping them to see the scope and potential impact of architectural (and atmospheric) intervention. 


\subsection{Atmospheric devices}

To feel the atmosphere they imagined, students translated the atmospheric grammar into architectural form, thereby engaging in a process of thinking through making [15]. The scale model is not only a miniature copy or representation of what ought to be or what is imagined, or an instrument of communication between an architect and its client. The model also constitutes a "machine" through which an architect can define and present his/her own worldview [16: pp. 61-68] "as a thinking mechanism used in making the invisible visible" [16: p. xxviii]. In class, models were also considered as "atmospherical devices" akin to the kinetic machines designed by Lásló Moholy-Nagy at the Bauhaus [17], which created spatial effects by using light in conjunction with perforated and transparent materials to cast changing shadows on surrounding surfaces. If the atmospherical prototypes were used to estimate and calculate atmospherical effects, they could come close to "qualitative" or "engineering models" [16: p. xx].

Instruction was given to create one or a series of atmospheric models using the same set of parameters, each of which suggests a variation of a general ambiance. One example (Fig. 3 ) is an interpretation of a fire camp set in the middle of a forest. The locations of the origin of heat radiation, color, and spacing of the surrounding trees (translated as columns) suggests the potential for differences in translation, and for varied effects. In regard to the latter, the vertical elements of the architectural model would, for example, grow in number and decrease in dimension, thus changing the shadows cast and filtering in a different way color, light, and even the temperature radiating from the center.

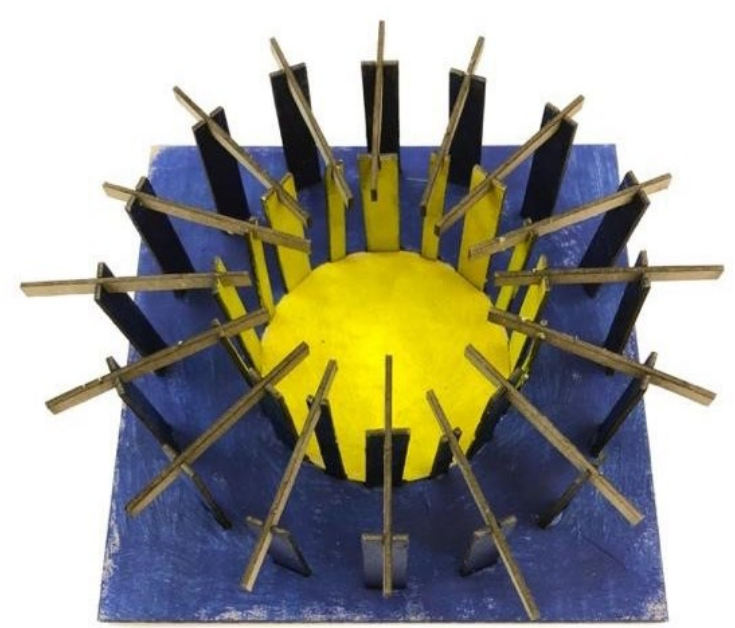

Fig. 4. Translation of the atmosphere of a fire camp surrounded by trees by Joshua Huang, Stuckeman School, spring 2018 course on atmospheres, Penn State. Image $\mathbb{C}$ Author.

The series of bathing experiences of the Therme Vals [9] designed by architect Peter Zumthor stands as a clear precedent, a spatial symphony around the different states and experiences of water, warm, cold, still, or in movement, infused with flower petals for 
aromatherapy ${ }^{3}$, to be tasted at time, resulting in an assemblage of atmospheres in connected parallelepipedal boxes, sharing similarities, yet different in regard to subtle variations in the atmospheric parameters, for example, temperature, sound, color, and light.

Parametric modeling tools enable the rapid production of a series of models, emphasizing the possible variation of form based on (sensory) data entry (Fig. 4). The exquisite 3D printed models that Thomas Leonard generated by transforming sound data into form are atmospheric because of their materiality and sensuous forms.

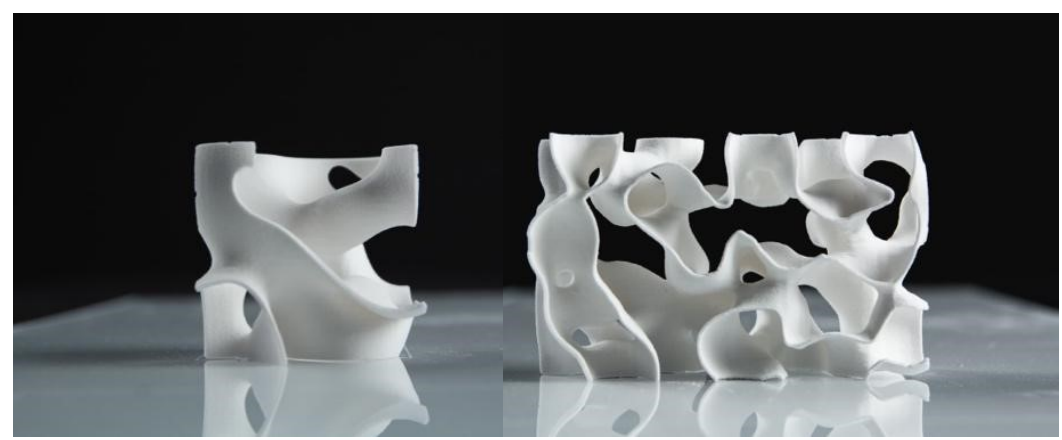

Fig. 5. Thomas Leonard, Turn Up The Volume, fall 2018. Atmospheres: Representation, Design and Fabrication research seminar, Penn State. Images (C) Thomas Leonard.

Through making atmospheric models, designers think of incorporating other parameters of ambiances into their atmospheric devices (for example, which absorbing or reflecting materials to use) to create an architecture that performs, akin to, for example, an orchestra of musical instruments or a fire camp in a forest to produce enchanting building atmospheres.

\section{Translation}

To this point, the discussion has focused on experimental ways to design meaningful atmospheres starting with choosing, sampling, and translating atmospheric and sensory data. Yet, many questions remain: What are we to make of parameters that are fleeting and intimately related to each other? Sound and smell, for example, travel with wind, which flows in particular directions in response to a variety of obstacles and surfaces. The students converted the data they collected, thereby iteratively transforming "matter" into "form," and with and between each operation, a "gap that no resemblance could fill" [14: p. 125] became apparent. For example, from soil to $\mathrm{pH}$, from $\mathrm{pH}$ to a roof with a rainwater collecting system. Unlike the scientific process, the design process is not so concerned with "reversibility" [14]. When the scientific process requires "circulating references," i.e., that one must be able to track original data entry [14], the "designerly ways of knowing" [18] welcome leaps from "matter" to "form" that creatively incorporate additional knowledge learned from generating the form itself. Thus, the data at the origin of the process becomes less distinct.

Because an atmosphere is dynamic, parametric modeling software and methods offer special opportunities to explore the computation of sensuous and immersive atmospheres.

\footnotetext{
${ }^{3}$ As seen in the video by Richard Compans, Les Thermes de Pierre (Arte + Centre Pompidou, 2001): https://www.youtube.com/watch?v=V1UVmNevN5s (Last accessed, February, 4, 2019).
} 
The experimentations described herein translate dynamic sensory data into atmospheric parameters and, more importantly, feelings into forms for informed spatial effects. Thus, in this work, we describe and propose an enhanced architectural curriculum that invites students to realize the importance of designing for and with the senses to create quality spaces. By exploring atmospheric variability that incorporates sensory data (related not only to vision, hearing, and touch, but also to smell and taste), changing environmental factors (air flow, light, and temperature) or situational "porosity," experienced as we move through space [19], designers explore hybridizing architecture with landscape. To "free architecture" from function [20], as architect Junya Ishigami puts it, to let architecture blend in with, become a part of, its milieu is integral to the purpose of the pedagogical practice described herein.

Through the various assignments focused on decoding and encoding a collection of sensory data, and inspired by lessons learned from, for instance, the drawings of architectural collective Archizoom, or the work of architect Peter Zumthor [9, 21], it became increasingly liberating to explore the performative potentials of drawing and modeling. These are the very processes used by architects to project - imagine and create - spaces of effect and affect to which we can memorably connect.

\section{References}

1. Pauly, D., Barragán, L. \& Habersetzer, J., Barragán: Space and Shadow, Walls and Colour (Birkhäuser, 2002)

2. Hildebrand, G. The Wright Space: Pattern and Meaning in Frank Lloyd Wright's Houses (The University of Washington Press, 1991)

3. Abbas, Y. "The Cartography of Ambiance," in Ambiances, Tomorrow-Ambiances 2016 Third International Congress, September 21-24, Proceedings, 1, pp. 253-258

4. Allen, S., Practice-Architecture, Technique and Representation (Routledge, 2009)

5. Alexander, C. A Pattern Language: Towns, Buildings, Construction (Oxford University Press, 1977)

6. Tschumi, B., Migayrou, F. \& Centre Georges Pompidou, Bernard Tschumi: Architecture: Concept \& Notation (Editions Du Centre Pompidou, 2014)

7. Capdevila, P. M., "The Interior City: Infinity and Concavity in No-stop City," Cuadernos de Proyectos Arquitectónicos, 2013, no. 4, pp. 130-132

8. Kanach, S. E. \& Lovelace, C. (Eds.), Iannis Xenakis: Composer, Architect, Visionary (Drawing Center, 2010)

9. Hauser, S. \& Zumthor, P., Peter Zumthor Therme Vals (Scheidegger \& Spiess, 2007)

10. Wigley, M., “Architecture of Atmospheres," Daidalos, 1998, no. 68, Constructing Atmospheres, pp. 18-27

11. Tschumi, B., "Operative Drawings" in Constant et al., The Activist Drawing: Retracing Situationist Architectures from Constant's New Babylon to Beyond (Drawing Center, 2001), pp. 134-137

12. Böhme, G., The Aesthetics of Atmospheres (Routledge, 2017)

13. Duffy, J. H. 2016, "Dubuffet plays hide-and-seek: Lineage, reflexivity, and perception in "Coucou bazar," Art Bulletin, vol. 98, no. 2, pp. 237-260

14. Latour, B., Pandora's Hope: Essays on the Reality of Science Studies (Harvard University Press, 1999) in Mello, L. and Byvanck, V. (Eds.) Dreaming Awake, Automatica, Marres, 2018) 
15. Ingold, T., Making: Anthropology, Archeology, Art and Architecture (Routledge, 2013)

16. Smith, A. Architectural Model as Machine: A New View of Models from Antiquity to the Present Day (Routledge, 2004)

17. Blume, T., Hiller, C., Stiftung Bauhaus Dessau, Henie-Onstad kunstsenter \& Kungnip Hyŏndae Misulgwan, Human-Space-Machine: Stage Experiments at the Bauhaus (Spector Books, 2014)

18. Cross, N., "Designerly Ways of Knowing," Design Studies, vol. 3, no. 4, October 1982, pp. 221-227

19. Janson, A., "Porosity: Ambiguous Figure and Cloud." In Feldhusen, S., Poerschke, U

20. Weidinger, J. (Eds.): "Mixings in Architecture and Landscape Architecture." CloudCuckoo-Land, International Journal of Architectural Theory, vol. 21, no. 35, 2016, http://cloud-cuckoo.net/fileadmin/issues_en/issue_35/article_janson.pdf (last accessed, February 9, 2019): pp. 35-46

21. Ishigami, J., Freeing Architecture (Fondation Cartier pour l'art contemporain/ LIXIL, 2018)

22. Zumthor, P., Atmospheres: Architectural Environments: Surrounding Objects (Birkhäuser, 2006) 